\title{
Hepatite D
}

\author{
Hepatitis D
}

José Carlos Ferraz da Fonseca'

Resumo O vírus da hepatite $D(V H D)$, também chamado de vírus delta, é um pequeno vírus contendo RNA circular. O VHD causa infecção, quando há coinfecção com o vírus da hepatite $B(V H B)$ em indivíduos normais ou superinfecção em portadores crônicos do VHB. Três genótipos já foram clonados e seqüenciados. A infecção apresenta distribuição mundial, sendo a região ocidental da Amazônia brasileira considerada área de alta endemicidade. Estima-se que 18 milhões de pessoas encontram-se infectadas pelo vírus entre os 350 milhões de portadores crônicos do VHB no mundo. As vias de transmissão do VHD e os fatores de risco mostram-se similares aos da infecção pelo VHB. O diagnóstico se faz pela identificação imuno-histológica do HDAg no fígado e pelo encontro das frações IgM e lgG anti-HD no soro por radioimunoensaio ou ELISA. O curso clínico da infecção pelo VHD mostra-se variável. Os pacientes podem apresentar formas fulminantes de hepatite. As formas crônicas associam-se a achados histopatológicos graves no fígado, com curso rápido e progressivo, evoluindo para cirrose, insuficiência hepática e morte. O interferon alfa constitui a única opção terapêutica com algum efeito benéfico no tratamento da hepatite. O transplante hepático encontra indicação nos casos terminais de cirrose. A profilaxia indireta da infecção pelo VHD tornou-se possível com o advento da vacina contra o vírus da hepatite $B$.

Palavras-chaves: Hepatite D. Hepatite B. Cirrose. Insuficiência hepática.

Abstract The hepatitis D virus (HDV), also called delta virus, is a small circular RNA virus. The HDV is dependent on the hepatitis $B$ virus (HBV) and can cause infection in normal individuals with hepatitis $B$ or yet, superinfect chronic HBV carriers. Three genotypes have already been cloned and sequenced. Infection with HDV has a worldwide distribution and a high HDV endemicity has been documented in the western Amazon region, in Brazil. It has been estimated that 18 million people are infected with this virus amongst the 350 million carriers of the HBV around the world. The HDV transmission and risk factors for infection are similar to those for HBV infection. The diagnosis is based on the immunohistological identification of HDAg in the liver and detection of IgM and Ig G anti-HD in serum using RIA or EIA. The clinical course of hepatitis $D$ is variable. Fulminant disease occurs more commonly in hepatitis $B$ and $D$ than in other forms of acute viral hepatitis. Chronic HDV infection is usually associated with severe histological changes in the liver and with a rapidly progressive course, that can lead to cirrhosis, liver failure and death. Treatment of chronic hepatitis $D$ is currently unsatisfactory and interferon alpha is the only agent found to have some effect on the course of chronic hepatitis. Orthotopic liver transplantation is indicated for terminal cases of cirrhosis. Prophylaxis for HDV infection is possible by vaccination against the hepatitis $B$ virus.

Key-words: Hepatitis D. Hepatitis B. Cirrhosis. Liver failure.

O vírus da hepatite D ou Delta (VHD), descoberto em 1977 por Rizzetto e cols ${ }^{43}$ é reconhecido como o mais patogênico e infeccioso entre os vírus hepatotrópicos ${ }^{13} 3742$. Ele possui notável poder de dominância e supressão sobre outros agentes virais, observando-se, por exemplo, o seu efeito dominante na coinfecção com o VHB e na tripla infecção com o
$\mathrm{VHB}+\mathrm{VHC}^{44}$. O VHD apresenta também efeito inibitório sobre a síntese dos antígenos virais do VHB durante a superinfecção, particularmente sobre 0 antígeno de superfície (HBsAg) e o antígeno central $(\mathrm{HBcAg})^{42}$. Em tripla infecção viral, a infecção pelo VHD associa-se à supressão da viremia do VHB e do vírus da hepatite $\mathrm{C}$, sendo maior no $\mathrm{VHC}$ do que no $\mathrm{VHB}^{23}$.

1. Fundação de Medicina Tropical, Manaus, AM.

Endereço para correspondência: Dr. José Carlos Ferraz da Fonseca. Gerência de Virologia/FMT-AM, Av. Pedro Teixeira 25, Planalto, 69040-000 Manaus, AM.

e-mail: fonseca@prodamnet.com.br

Recebido para publicação em 15/10/2001. 
No mundo, em especial em áreas endêmicas, a infecção pelo VHD provoca formas graves de hepatite, determinando hepatite fulminante ${ }^{21618212442}$, o agravamento das lesões de hepatite crônica e potenciando a rápida progressão para cirrose hepática ${ }^{131442}$, fatos estes comumente observados na Amazônia ocidental brasileira ${ }^{213141618}$.

\section{O AGENTE VIRAL}

De composição híbrida e defectiva, o VHD apresenta-se biologicamente como o único agente satélite e subviral humano que depende exclusivamente da função ajuda provida pelo DNA do vírus da hepatite $B$ (HBV-DNA) e de seu respectivo envelope de proteínas, o antígeno de superfície do VHB (HBsAg), para completar o seu ciclo biológico, ou seja, de replicação, de transmissão e infectividade e de penetração e replicação exclusiva nos hepatócitos ${ }^{42}$. Portanto, o VHD não é um vírus hepatotrópico autônomo. Apesar de a replicação exclusiva do VHD ocorrer nos hepatócitos, até o momento não foram identificados receptores para o VHD nestas células.

Considerado como subvírus satélite do VHB e de outros pertencentes à família hepaDNAvírus (vírus da hepatite da marmota, do pato de pequim, do esquilo), - VHD é constituído de uma pequena partícula esférica, envelopada, organizada e medindo cerca de $36 \mathrm{~nm}$, variando de $35 \mathrm{~nm}$ a $37 \mathrm{~nm}^{30} 42$ (Figura 1). Esta partícula reveste-se externamente pelo $\mathrm{HBsAg}$, e no interior do virion encontra-se o antígeno da hepatite D (HDAg) e o genoma circular constituído de ácido ribonucléico (HDV-
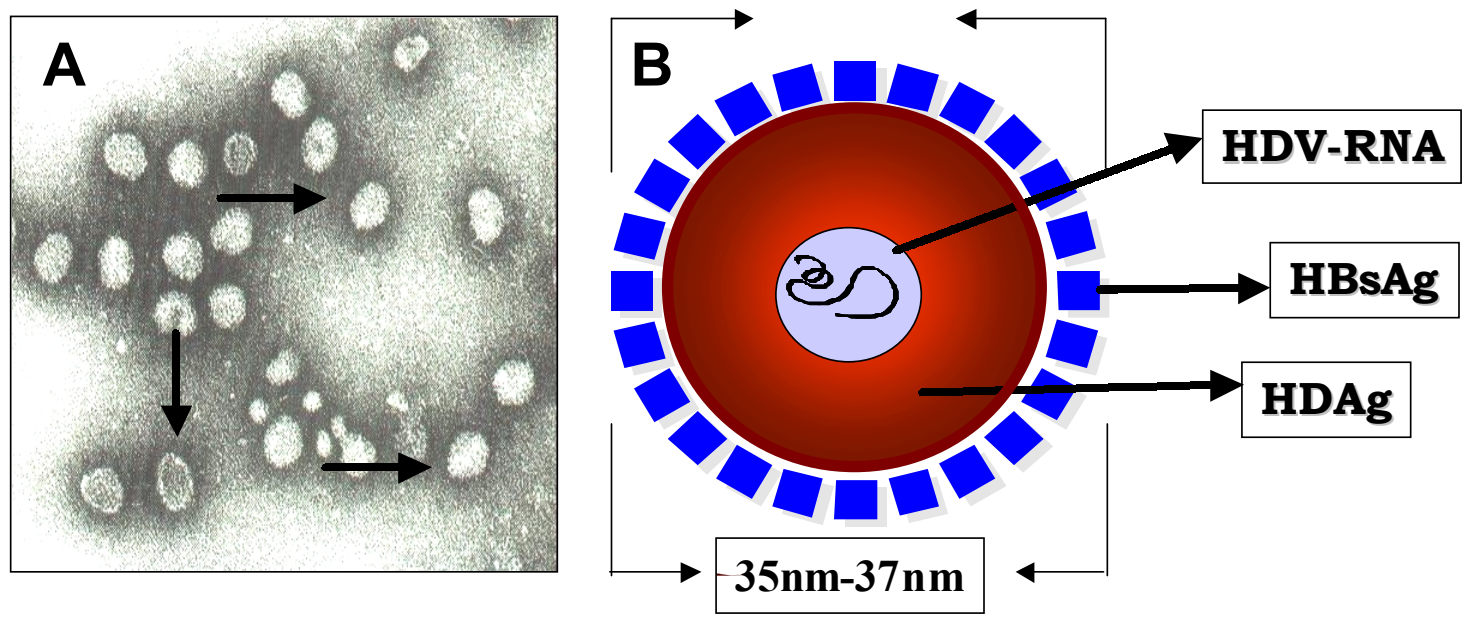

Figura 1 - A) MIcroscopia eletrônica do VHD, setas (Cortesia do Dr.Mario Rizzetto, Turim, Itália). B) Representação esquemática da partícula do VHD com envoltório do VHB (HBsAg).

RNA), como podemos observar também na Figura 1. A classificação do VHD como subvírus satélite do VHB baseia-se nos princípios biológicos de que o VHD compõe-se de RNA, de pequeno tamanho, de cadeia simples, circular e defeituoso, de não infectar na ausência do VHB e finalmente de depender da função ajuda de um vírus constituído de $\mathrm{DNA}^{30} 42$. Na parte externa do VHD observa-se envelope lipídico derivado do VHB e no interior do virion encontra-se o seu antígeno, o HDAg, único e específico, composto de duas proteínas, uma curta (short) denominada de HDAg-S e outra longa (long) chamada de HDAg-L, com 24 kilodaltons (195 aminoácidos) e 27 daltons (214 aminoácidos) de peso molecular, respectivamente ${ }^{3342}$. A forma curta (HDAg-S) é requerida para a replicação viral do RNA e a longa (HDAg-L) para inibir a replicação do RNA e promover o empacotamento do RNA nos virions. Este antígeno com duas formas de proteínas localiza-se no núcleo das células hepáticas. Observa-se também pequeno genoma constituído de ácido ribonucleico (RNA), com 1,75 kilobases $(\mathrm{kBa})$ de comprimento ${ }^{30} 42$.
O genoma do vírus $D$, após desnaturação, apresenta RNA único, enrolado e circular contendo 1676-1683 nucleotídeos, similar aos genomas dos virióides vegetais e virusóides ${ }^{3542}$. O RNA do vírus $D$ e os virióides vegetais provavelmente apresentam ancestral comum e são fósseis vivos de um mundo RNA pré-celular que antecede a diferenciação das informações genéticas do DNA e das funções enzimáticas em proteínas ${ }^{35} 42$. $O$ genoma do VHD mostra-se maior do que o RNA dos viróides e bem menor que os do Picornavírus.

$\mathrm{Na}$ ocorrência da infecção pelo VHD, o VHB empresta a este patógeno as partículas de HBsAg, que servirão de invólucro ao VHD, protegendo desta maneira a sua integridade e a capacidade de se tornar infectante aos humanos ${ }^{30} 42$. O HBsAg do invólucro do VHD constitui-se de três tipos de proteínas. A primeira, codificada pelo gene $S$ do HBV-DNA, a segunda pela sequência de 55 aminoácidos da região Pré $S_{2}$ e, a terceira, constituída de 108 -119 aminoácidos da região Pré $\mathrm{S}_{1}$. O revestimento externo do VHD pelo HBsAg impede a hidrólise interna do RNA do vírus $\mathrm{D}^{42}$. 
Estudos genéticos e seqüenciais do genoma do VHD revelam alta heterogeneidade deste vírus, com várias seqüências isoladas, sendo identificados três genótipos do VHD, diferenciados e denominados de tipos I, II (Ila,Illb) e $\mathrm{III}^{74}$. Mais recentemente, estudos de análise

\section{EPIDEMIOLOGIA E TRANSMISSÃO}

Em áreas endêmicas de hepatite $B$, a infecção pelo VHD representa grave problema de saúde pública. Estima-se que 18 milhões de pessoas encontram-se infectadas pelo VHD entre os 350 milhões de portadores crônicos do VHB no mundo. O estado de portador crônico do VHB (HBsAg positivo) constitui-se no principal fator epidemiológico para a propagação do VHD, o que ocorre, por exemplo, entre as populações nativas da Amazônia brasileira' 2419 15 , peruana $^{8}$ e venezuelana ${ }^{21} \mathrm{e}$, em determinadas áreas da África ${ }^{27}$. $\mathrm{O}$ mesmo fator epidemiológico aplica-se aos grupos de alto risco para hepatite $B$, como os toxicômanos, os hemodializados e os politransfundidos ${ }^{13}{ }^{42}$. Estudos atuais revelam diminuição da prevalência da infecção pelo VHD na Itália, sugerindo os autores que, tal fato, explica-se pela redução de portadores crônicos do VHB, em razão da alta cobertura vacinal contra a hepatite $B$ entre os habitantes daquele país ${ }^{52}$.

A taxa de infecção pelo VHD mostra-se baixa na Ásia, independente da alta prevalência de portadores do VHB na população ${ }^{9}$. A explicação para esses dados seria que o VHD ainda não encontra-se difundido na população geral, ou então, de que há resistência genética dessas populações à infecção pelo VHD' ${ }^{9}$ Em países de baixa prevalência de infecção pelo VHB, a do genoma do vírus, em africanos, sugerem a existência de mais três genótipos do $\mathrm{VHD}^{40}$. Cada genótipo do vírus $\mathrm{D}$ apresenta distribuição geográfica diferente e doença hepática associada, sendo o subtipo la e o tipo III considerados os mais patogênicos 783240494647 .

infecção pelo vírus Delta afeta os grupos de alto risco ${ }^{1342}$. Em nosso país, excetuando a região Amazônica ocidental e oriental, a prevalência de infecção por este patógeno mostra-se desprezível, seja em grupos de risco ou na população geral ${ }^{13}$.

Com relação à distribuição geográfica dos genótipos do VHD, observe que o tipo I prevalece nos Estados Unidos da América do Norte ${ }^{7}$, Europa ${ }^{32}$, Norte da África ${ }^{53}$, Ásia ${ }^{49}{ }^{50}$ e Sul do Pacífico ${ }^{46}$. Descreveu-se o tipo II na Ásia, especialmente no Japão e Taiwan ${ }^{49}{ }^{50}$, enquanto o tipo III tem sido relatado apenas na América do Sul ${ }^{839}$.

A transmissão do VHD ocorre principalmente por via parenteral e apresenta os mesmos mecanismos de transmissão do $\mathrm{VHB}^{13}{ }^{42}$. Contudo, em determinadas áreas do norte da América do Sul, a exemplo da Amazônia brasileira e venezuelana, a transmissão do VHD poderia ocorrer por exposição inaparente, principalmente relacionada com efrações da pele por picadas de insetos ou através das mucosas ${ }^{13} 21$. A transmissão perinatal, depende da infectividade do VHB, ocorrendo em mães portadoras do VHB com sinais sorológicos de replicação viral, por exemplo, $\mathrm{HBeAg}$ positivas ou anti-HBe+/HBV-DNA positivas ${ }^{13}{ }^{42}$. $\mathrm{Na}$ Tabela 1, alinham-se os principais fatores de risco na infecção simultânea (coinfecção) com o VHB e na superinfecção aguda pelo VHD em portadores do VHB.

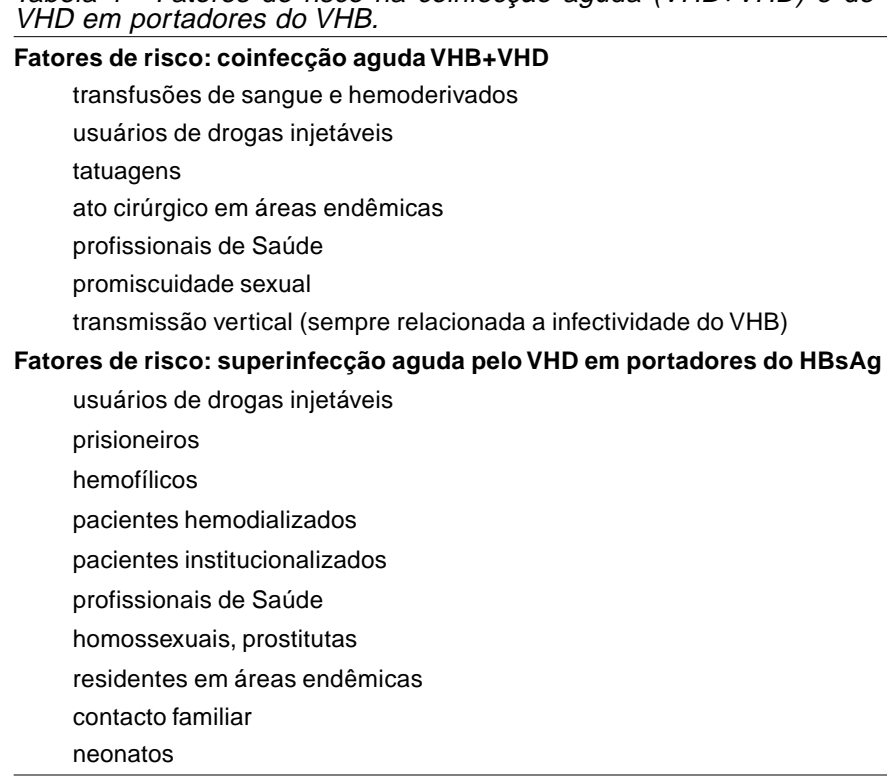

Com relação aos dados demográficos, a infecção pelo VHD acomete principalmente pacientes do sexo masculino, fato este decorrente da maior prevalência do VHB neste $\operatorname{sex}^{19}$. Quanto à relação entre a infecção 
pelo VHD e o grupo etário, observa-se maior prevalência em menores de 15 anos de idade, fato este relatado na Amazônia brasileira e relacionado à precocidade da infecção pelo VHB ${ }^{12415}$. Em outros países, a infecção por este patógeno alcança maior prevalência entre a terceira e a quarta décadas de vida ${ }^{42}$.

Estudos realizados em nossa região, sobre a prevalência do VHB e VHD entre familiares de portadores de ambos os vírus, sugerem que os familiares constituem reservatórios para a transmissão da infecção e que os irmãos são de grande importância para a circulação do VHB e VHD, adquirindo a transmissão caráter horizontal e familiar ${ }^{5}$. Estudos de biologia molecular, com seqüência única do HDV-RNA e predominância do genótipo I, indicam que a transmissão do VHD entre familiares ocorre através de contato pessoal ${ }^{31}$. A análise da seqüência do genoma do VHD revelou evidências da transmissão do VHD entre casais, sugerindo os autores deste estudo que a transmissão do VHD por via sexual possa ocorrer ${ }^{50}$. Mais recentemente, estudos realizados em sete grupos indígenas do Estado do Amazonas, sugerem que a transmissão sexual representa o mecanismo mais importante na disseminação do VHD na população ${ }^{4}$.

Fatores ambientais e culturais relacionados com o comportamento humano e com a presença de reservatórios animais ou infestação por insetos poderiam influenciar a circulação do $\mathrm{VHD}^{13}{ }^{42} \mathrm{Na}$ Amazônia brasileira, área de alta prevalência e incidência de malária, como também de alta densidade de mosquitos, observa-se nas calhas dos rios sabidamente malarígenos alta prevalência de infecção pelo $\mathrm{VHB}$ e $\mathrm{VHD}^{15}$, fato este não observado entre indivíduos residentes em calhas de rios não malarígenos ${ }^{1}$.

O período de incubação em humanos ocorreria em torno de 35 dias, enquanto em chimpanzés previamente infectados pelo VHB, varia de 28 dias a 180 dias $^{42}$.

\section{PATOGÊNESE}

Estudos experimentais e clínicos indicam que o vírus Delta mostra-se invariavelmente patogênico para a célula hepática ${ }^{3342}$ e, dependendo do tipo de infecção, ocasiona formas graves de hepatite aguda, inclusive com morte ou freqüente progressão para a cronicidade 213141842 . Discute-se, ainda, quais os possíveis mecanismos patogênicos da hepatite viral. De acordo com estudos recentes, dois possíveis mecanismos explicam sua patogenicidade ${ }^{33}$. O primeiro ocorre pela ação citopática direta do VHD após a expressão do HDAg na membrana dos hepatócitos ou através da replicação de seu genoma (HDV-RNA) e conseqüente destruição celular. A ação citotóxica do HDAg associada à replicação do HDV-RNA poderia ser considerada o outro mecanismo ${ }^{33}$.

A autoimunidade também contribui para a destruição do hepatócito. Documentou-se a presença de auto anticorpos microssomais contra o citoplasma dos hepatócitos e túbulos proximais renais em pacientes com hepatite crônica tipo $D$, denominado de anti$\mathrm{LKM}^{42}$. O processo de autoimunidade ocorre de forma rotineira na coinfecção aguda pelo VHB e VHD, com a identificação dos anticorpos contra as células da camada basal e contra as células epiteliais estriadas tímicas. Em pacientes com hepatite crônica tipo D, observa-se alta freqüência de anticorpos contra a lâmina nuclear C $(80 \%)$ e para o anti-LKM3 $(58,3 \%)^{35}$.
O curso da infecção pelo VHD pode ser modificada por diversos fatores, a exemplo da superinfecção aguda pelo VHD em portadores do VHB mutante 6 . Nestes, a replicação do VHD ocorre com menor eficiência, em razão da menor ajuda funcional do VHB mutante, e observa-se curso clínico assintomático, sem exacerbação aguda da doença hepática ${ }^{6}$.

Importa ainda conhecer o status da infecção pelo VHB, se latente ou em replicação. No caso de infecção latente do VHB, sem sinais maiores de replicação viral (HBeAg e HBV-DNA negativos), a infecção pelo VHD apresenta evolução lenta para a cronicidade. Em atividade de replicação, o VHB oferece condições biológicas ao VHD e ajuda necessária para que este patógeno se dissemine célula-a-célula, aumentando a sua agressividade ${ }^{1342}$.

$\mathrm{Na}$ formas graves da doença, diversos autores sugerem que a gravidade encontra-se relacionada a cepas variantes do VHD ${ }^{16}{ }^{18}$. Recentemente, novos estudos implicam o genótipo III do VHD associado ao subtipo $\mathrm{F}$ do $\mathrm{VHB}$, como responsáveis por formas graves de hepatite que acometeram militares peruanos na bacia amazônica peruana ${ }^{8}$.

Em indivíduos sorologicamente reativos para os anticorpos contra o HBsAg (anti-HBs), a infecção pelo VHD não se estabelece ${ }^{42}$.

\section{ASPECTOS CLÍNICOS E EVOLUTIVOS}

Considerando os diversos mecanismos de infecção do VHD, os aspectos clínicos e evolutivos da infecção por este vírus divergem de outros vírus hepatotrópicos. Na infecção simultânea VHB + VHD (coinfecção aguda), e após o estabelecimento do VHD, este último provoca interferência viral e inibe a síntese do VHB. Portanto, a coinfecção aguda B e D apresenta-se como hepatite aguda recidivante, de curso clínico bifásico, com dois picos séricos das aminotransferases. Tal padrão recidivante ocorre com maior freqüência do que na clássica hepatite aguda $B$ e relaciona-se à expressão seqüencial dos vírus $B$ e $D^{43}$.

Na maioria dos casos, o quadro clínico da coinfecção aguda VHB+VHD evolui com hepatite aguda benigna. Excepcionalmente, a síntese do VHD torna-se intensa, soma-se aos efeitos ocasionados pelo VHB, e leva a 
formas fulminantes e crônicas de hepatite 2161842 . O prognóstico da coinfecção $B$ e $D$, mostra-se benigno, ocorrendo completa recuperação e eliminação dos vírus B e D em $95 \%$ dos casos $^{13} 42$

Na superinfecção pelo VHD em portadores do HBsAg sintomáticos ou assintomáticos, com sinais ou sem sinais sorológicos de replicação do VHB, o prognóstico revela-se mais grave. Entre os portadores do HBsAg, o VHD encontra nos hepatócitos antigenemia pré-existente do VHB, condição esta ideal para que o vírus D inicie replicação intensa, explosiva e, em conseqüência, produza grave dano hepático ${ }^{13} 42$. Independentemente da gravidade da superinfecção pelo VHD, não há diferenças clínicas e bioquímicas distintas da hepatite aguda pela coinfecção $V H B+V H D^{42}$. Contudo, o prognóstico revela-se bem diferente, e na superinfecção o índice de cronicidade torna-se significativamente maior $(79,9 \%)$ do que na coinfecção (3\%), ou na clássica hepatite B. Em adultos, portadores do HBsAg e infectados pelo VHD, o período de progressão para a cronicidade varia de dois a seis anos, enquanto em crianças a evolução para a cronicidade ocorre mais rapidamente ${ }^{1342}$.

Nos pacientes com doença hepática crônica pelo VHB pré-existente, a superinfecção pelo VHD agrava o quadro clínico, bioquímico e histológico ${ }^{1342}$.

A participação do VHD na oncogênese hepática tem sido sugerida mas, a associação do VHD ao hepatocarcinoma não parece ser freqüente. No entanto, a superinfecção pelo VHD em crianças e jovens portadores do VHB pode acelerar a evolução para cirrose hepática e, conseqüentemente, representar risco para o desenvolvimento de hepatocarcinoma ${ }^{42}$. No Brasil, apesar de a infecção ocorrer em jovens, não se observou prevalência significativa do vírus delta no carcinoma hepático ${ }^{13}$.

Em regiões tropicais as formas fulminantes de hepatite, geralmente acometendo crianças e adultos jovens, apresenta características histopatológicas diferentes dos padrões clássicos (necrose hepática maciça), como relatado no norte da América do

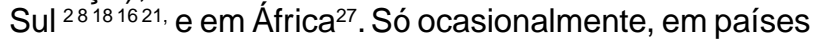
desenvolvidos, observa-se esta mesma forma peculiar de hepatite fulminante Delta ${ }^{42}$.

Na forma fulminante de hepatite $D$ e de ocorrência nos países tropicais, observa-se no tecido hepático a presença marcante de necrose eosinofílica, esteatose microvesicular (células em mórula) e a presença do HDAg no núcleo dos hepatócitos ${ }^{2}{ }^{18}$. Mais tarde, observou-se que tal padrão histopatológico não era patognomônico da superinfecção pelo VHD, podendo ocorrer também nas formas fulminantes de hepatite, seja por coinfecção aguda VHB+VHD ou por outros vírus hepatotrópicos, tais como os vírus das hepatites $A, B$ e $C^{16}$. Atualmente, sugere-se que a evolução e o prognóstico da infecção pelo VHD depende essencialmente dos genótipos virais, tipos I, II e III 783549 .

\section{DIAGNÓSTICO LABORATORIAL}

O diagnóstico laboratorial da infecção pelo VHD revela-se complexo em decorrência de sua própria história natural (tipos de infecção) e da utilização de diversos marcadores virais, tanto do VHB como do VHD, pela pesquisa de antígenos virais ou através da identificação de anticorpos específicos. Na Tabela 2,

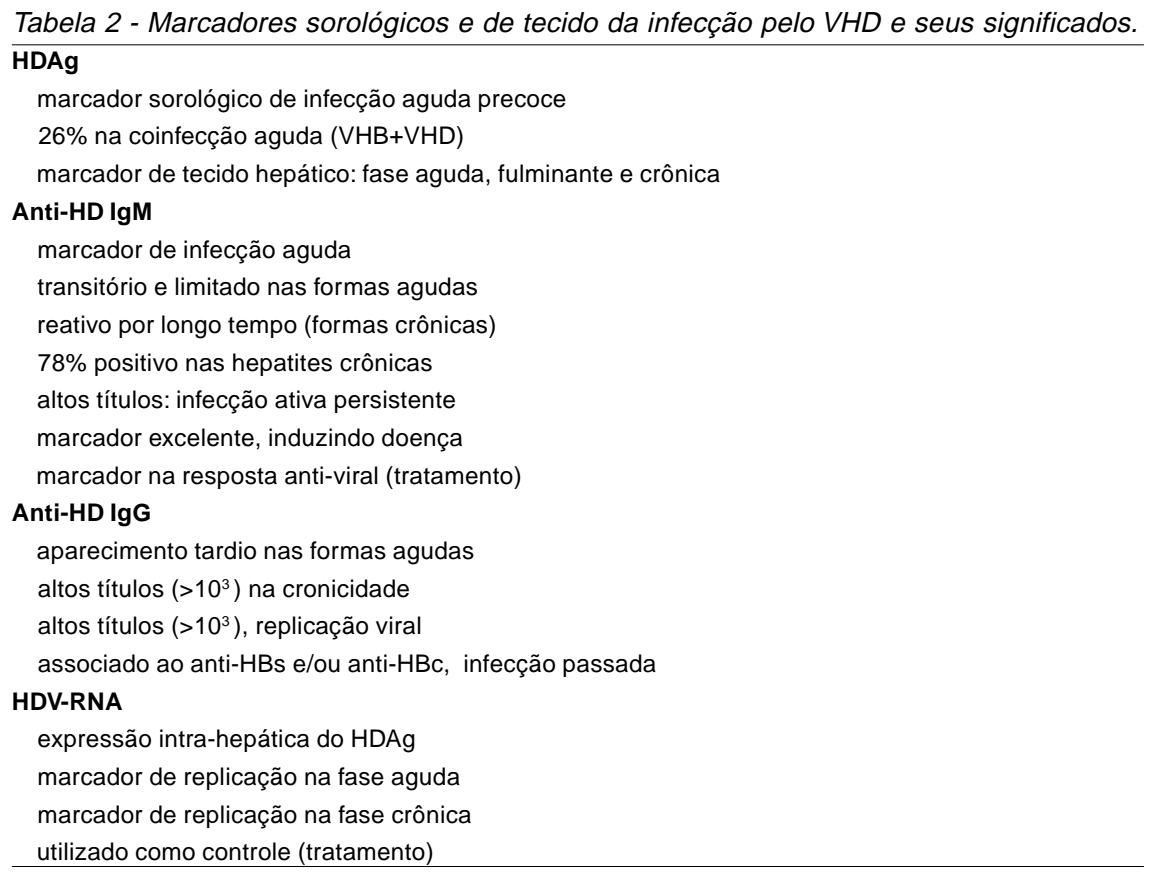


apresenta-se os principais marcadores sorológicos de infecção pelo VHD e os seus significados.

O encontro do HDAg em tecido hepático constitui o principal exame laboratorial utilizado no diagnóstico das diversas formas clínicas de hepatite $D^{30}$. Identifica-se o antígeno utilizando-se as técnicas de imunoperoxidase ou imunofluorescência. Ele localiza-se no núcleo dos hepatócitos, e pode, ocasionalmente, ser localizado no citoplasma em fases mais avançadas da doença ${ }^{30}$.

A identificação do HDAg no soro também revestese de importância pois assinala a fase mais precoce da infecção primária ${ }^{30}$. Para o sorodiagnóstico da hepatite aguda D (coinfecção ou superinfecção), destaca-se a detecção da fração IgM anti-HD ${ }^{30}$, através das técnicas imunoenzimática (ELISA) ou de radioimunoensaio (RIA).

A persistência da fração IgM anti-HD no soro dos pacientes que desenvolvem a forma aguda de hepatite D, tanto por coinfecção, como por superinfecção, prediz a tendência a cronicidade, com evolução para cirrose ${ }^{17}$ 30. Em nossa casuística, observamos que $74,5 \%$ dos nossos pacientes com doença hepática crônica $D$ eram reativos para a fração IgM anti-HD, sendo esse anticorpo demonstrado em $100 \%$ dos pacientes com hepatite crônica persistente. Identificou-se o anticorpo IgM também em $71,4 \%$ dos indivíduos com hepatite crônica ativa e em $76,5 \%$ dos que evoluíram com cirrose hepática ${ }^{17}$. A alta positividade para a fração IgM anti-HD nos pacientes cirróticos indica a manutenção da atividade replicativa do VHD por longo período ${ }^{1730}$. Nos pacientes com hepatite aguda $D$, a produção da fração IgM antiHD surge e desaparece rapidamente ${ }^{30}$.

No curso da coinfecção aguda VHB+VHD, o perfil sorológico sugere infecção aguda pelo VHB, identificando-se a fração anti-HBc IgM, sem a expressão da antigenemia $D^{30}$. A expressão dos marcadores sorológicos do VHD dar-se-á quatro a oito semanas após a exposição, com aparecimento inicial do HDV-RNA, seguido do aparecimento do HDAg e posteriormente da fração anti-HD lgM. A expressão inicial do VHB provoca um pico maior da alaninaminotransferase (ALT), ocorrendo o segundo pico da ALT na expressão do VHD ${ }^{30}$. $\mathrm{Na}$ Tabela 3, alinham-se os perfis sorológicos de coinfecção aguda pelos vírus das hepatites B e D.

Tabela 3 - Perfil sorológico da coinfecção aguda pelos VHB e VHD. Coinfecção aguda

Perfil tipo 1 (fase precoce de infecção por ambos os vírus, VHB e VHD): a) Perfil sorológico do VHB (HBsAg, HBeAg, anti-HBc IgM, HBV-DNA); b) Perfil sorológico do VHD (HDAg, anti-HD IgG, anti-HD IgM, HDV-RNA). Perfil tipo 2 (fase tardia de infecção por ambos os vírus, VHB e VHD) a) Perfil sorológico do VHB (HBsAg, anti- $\mathrm{HBe}$, anti-HBc IgM, HBV-DNA) b) Perfil sorológico do VHD (Anti-HD IgG, anti-HD IgM, HDV-RNA)

Na superinfecção aguda pelo VHD em portador do VHB (HBsAg reativo), ou seja, com antigenemia VHB préexistente, o perfil sorológico revela-se mais simples. Neste tipo de infecção, não se encontra a fração anti-HBc lgM e ocorre a positividade para o $\mathrm{HBeAg}$ ou anti-HBe, dependendo do estado de portador do HBsAg. A expressão do VHD neste caso mostra-se semelhante ao observado na coinfecção ${ }^{23}$. Na Tabela 4, resume-se os diversos perfis sorológicos típicos e atípico da superinfecção aguda pelo VHD em portador crônico do VHB.

Tabela 4 - Perfil sorológico da superinfecção aguda pelo VHD em diferentes padrões sorológicos de portadores do VHB.

Superinfecção aguda pelo VHD em portadores do VHB

Perfil tipo 1 (fase inicial de infecção do VHD):

a) Perfil sorológico do VHB (HBsAg, $\mathrm{HBeAg}$ ou anti $\mathrm{HBe}$, anti-HBc $\lg \mathrm{G}$ )

b) Perfil sorológico do VHD (HDAg, HDV-RNA)

Perfil tipo 2 (fase tardia de infeccão pelo VHD):

a) Perfil sorológico do VHB (HBsAg, $\mathrm{HBeAg}$ ou anti-HBe, anti-HBc $\lg G$ )

b) Perfil sorológico do VHD (Anti-HD IgG, anti-HD IgM, HDV-RNA)

Perfil tipo 3

a) Perfil sorológico do VHB (HBsAg, anti-HBc lgG)

b) Perfil sorológico do VHD (Anti-HD IgG, anti-HD IgM, HDV-RNA)

Perfil tipo 4 (atípico)

a) Perfil sorológico do VHB (HBsAg indetectável temporariamente*, antiHBs)

b) Perfil sorológico do VHD (HDAg, HDV-RNA)

* Supressão temporária do HBsAg (soro) na superinfecção aguda pelo VHD

O diagnóstico da infecção aguda pelo VHD, seja por coinfecção ou superinfecção, pode ser melhor entendido se utilizarmos o fluxograma resumido na Figura 2.

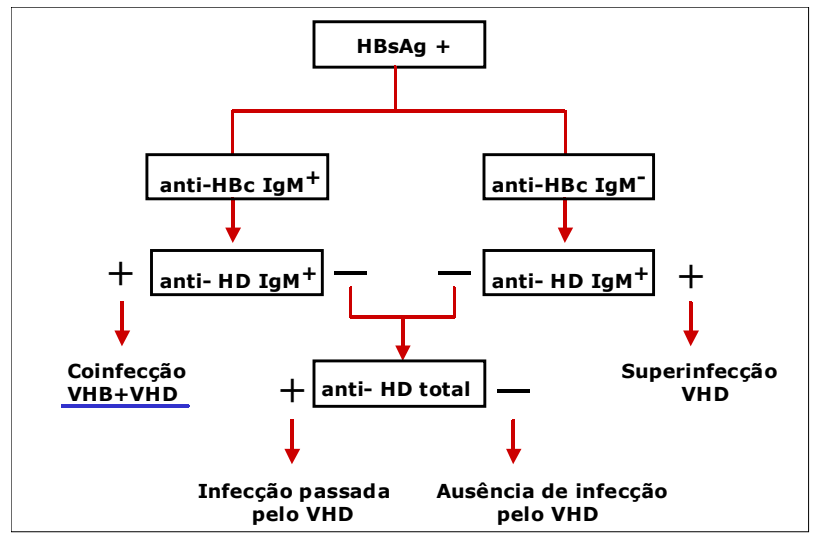

Figura 2 - Fluxograma para o diagnóstico da infecção aguda pelo VHD. + positivo; - negativo.

Nas formas crônicas de hepatite $D$, o diagnóstico sorológico baseia-se na detecção da fração IgM antiHD ou IgG anti-HD com altos títulos (1 título > 1/100.000) e a confirmação da presença do HDAg no tecido hepático $^{30}$. O isolamento do RNA do VHD no soro ou no tecido hepático, através das técnicas de hibridização molecular e PCR (Polymerase Chain Reaction), possui importância no diagnóstico da hepatite crônica Delta e sua presença indica alta infectividade ${ }^{30}$. O HDV-RNA persistentemente positivo no soro no estágio agudo de infecção, indica a progressão para a cronicidade em 
portadores do HBsAg com infecção aguda D. O seu desaparecimento resultaria em hepatite aguda $D$ auto-limitada ${ }^{30}$. Através de técnicas de análise genética de PCR-amplificado do genoma VHD, diretamente clonado e seqüenciado ${ }^{7}$, o diagnóstico laboratorial da infecção pelo vírus $D$, apesar da complexidade deste método e de não ser utilizado na rotina, tornou-se mais preciso, principalmente no que tange ao conhecimento da gravidade da infecção e de seu prognóstico ${ }^{8}$.

\section{TRATAMENTO}

O tratamento da infecção crônica pelo VHD objetiva a eliminação precoce do vírus, a interrupção da replicação viral, e a redução das aminotransferarases e do processo inflamatório crônico do fígado. O tratamento deve também contemplar a infecção concomitante pelo vírus $\mathrm{B}$. $\mathrm{Na}$ Tabela 5, descrevem-se os resultados esperados do tratamento da hepatite crônica D.

Tabela - 5 Resultados esperados no tratamento da hepatite crônica delta.

Supressão sustentada da replicação do VHD

HDV-RNA indetectável no soro

soroconversão de anti-HD IgM para anti-HD IgG

soroconversão de $\mathrm{HBsAg}$ para anti-HBs

Remissão da doença hepática

normalização da ALT no soro

diminuição do processo necro-inflamatório no fígado

diminuição da fibrogênese hepática

Melhora na evolução clínica

redução do risco de cirrose e hepatocarcinoma

maior sobrevivência

O interferon alfa (IFN) constitui a única opção terapêutica no tratamento das hepatites crônicas pelo VHD, já que as outras drogas anti-virais, como a ribavirina e a lamivudina, não apresentaram resultados satisfatórios ${ }^{2022}$. Considerando a rápida progressão da infecção Delta para as formas crônicas de hepatite, 0 único fator determinante da resposta ao IFN seria o tempo de duração da infecção pelo vírus D. Portanto, quanto mais precoce o diagnóstico e o início da terapêutica com o medicamento, melhor será a resposta clínica.

$\mathrm{Na}$ tentativa de se obter boa resposta bioquímica e virológica à infecção pelo VHD, utilizaram-se altas doses de IFN. Com doses de Interferon de 9 milhões de unidades, três vezes por semana, por um período de sete meses, observou-se melhora de todos os parâmetros medidos mas houve recaída freqüente após a interrupção do tratamento ${ }^{12}$.

Outros estudos utilizando doses ainda maiores de interferon alfa (18 milhões de unidades por dia) mostraram também apenas benefícios transitórios ${ }^{28}$.

Observaram-se melhores resultados com o uso prolongado de Interferon beta, em pacientes não respondedores ao Interferon alfa $^{34}$. Neste estudo, foram tratados 5 pacientes com $6 \mathrm{MU}$ e 9 pacientes com 9 $\mathrm{MU}, 3$ vezes por semana, por via intramuscular, durante 12 meses. Os resultados deste estudo revelaram ao fim do tratamento a normalização das aminotransferases em $7 / 9(77,7 \%)$ e 2 (22\%) negativaram a fração anti-
HD IgM. Um paciente clareou a infecção pelo VHB e pelo VHD. Não houve efeitos colaterais e, segundo os autores, o interferon beta em altas doses e por tempo prolongado representa nova opção terapêutica no tratamento da hepatite crônica pelo VHD.

Em nossa experiência (dados não publicados), de 18 pacientes (14 homens) tratados com Interferon alfa-2b (9MU), $3 \times$ por semana, durante um tempo médio de 26,5 meses, apenas três pacientes mantiveram as aminotransferases normais, apesar da permanência e positividade para o $\mathrm{HBsAg}$ em todos, do anti-HD lgM em $14 / 18(77,8 \%)$ e do anti-HD total em todos os 18 pacientes.

Em crianças portadoras de hepatite crônica Delta e tratadas com Interferon, os resultados obtidos não diferem dos resultados encontrados nos adultos ${ }^{11}$.

Em suma, o tratamento da hepatite crônica $D$ com altas doses de IFN alfa ou beta, em adultos ${ }^{122934} \mathrm{ou}$ em crianças ${ }^{11}$, revelou apenas a normalização das aminotransferases e diminuição da replicação viral durante o uso dos medicamentos, com recaída após o término do tratamento, ou ainda, exacerbação da doença hepática crônica, caraterizada por piora da função hepática ${ }^{10}$. O uso do interferon no tratamento da hepatite crônica Delta deve ser feito por longo tempo ou continuamente. Destaca-se o relato recente de resolução da hepatite crônica pelo VHD após 12 anos de terapia com Interferon, com negativação sorológica do HBsAg e HDV-RNA, e melhora significativa do processo de fibrose hepática ${ }^{26}$. Todavia, em razão dos efeitos colaterais desta droga e dos próprios efeitos patogênicos do VHD, a indicação do interferon tornase limitada na hepatite crônica tipo D.

O tratamento da hepatite crônica pelo VHD com Inteferon alfa-2b em pacientes com infecção ou não pelo vírus humano da imunodeficiência (HIV) revelou resultados interessantes ${ }^{38}$. Utilizando doses de 10 MU $3 \times$ por semana por seis meses e doses adicionais de $6 \mathrm{MU} 3 \times$ por semana por mais seis meses, os autores observaram normalização das aminotransferases em $19 \%$ dos pacientes infectados pelo HIV e em $14 \%$ de pacientes não infectados pelo HIV durante o primeiro ano. Dois anos após a suspensão da terapêutica, um paciente HIV positivo e dois HIV negativos mostraram resposta sustentada, tanto bioquímica (aminotransferases), como virológica e histológica. Concluem os autores que o Interferon deve ser indicado em pacientes imunocompetentes coinfectados com o VHD e HIV, considerando a rápida evolução do VHD para doença hepática grave ${ }^{38}$. 
A primeira tentativa de transplante hepático em pacientes com cirrose hepática tipo $B$ e $D$, resultou em complicações graves, inclusive óbitos e reinfecção pelo $\mathrm{VHD}^{41}$. De acordo com os autores, o transplante de fígado em sete pacientes não se sustentou. Destes, dois clarearam o HBsAg e o HDAg, e, durante o seguimento de 14 e 15 meses, comportaram-se clinicamente sem maiores alterações. Em cinco pacientes constatou-se a recorrência da infecção pelo VHD com quadro de hepatite em três, e um óbito; o outro, recebeu novo transplante, porque houve reinfecção pelo VHD. Neste grupo de sete pacientes, antes do transplante hepático, em todos havia a presença do anticorpo contra o HBsAg (anti-HBs), em função do uso da imunoglobulina antiHBs e da vacinação contra o VHB. Concluem os autores que os pacientes transplantados com cirrose Delta facilmente desenvolvem reinfecção pelo $\mathrm{VHD}^{41}$.

Outro estudo revelou melhor evolução no póstransplante. Houve sobrevida de cinco anos em $88 \%$ dos transplantados, e reativação do HBsAg em 13,2\% ${ }^{50}$.

Outras drogas antivirais, como a lamivudina, no tratamento do pré ou pós-transplante hepático, não mostraram resultados consistentes ${ }^{36}$. Mais recentemente, estudos com a lamivudina em pacientes com hepatite crônica $D^{25}$, na dose de $100 \mathrm{mg} / \mathrm{dia}$, por via oral e por um período de 12 meses, revelaram que o medicamento é bem tolerado, com negativação do
HBV-DNA em $80 \%$ dos casos. Contudo, todos os pacientes tratados permaneceram positivos para 0 HBsAg e HDV-RNA ao final do tratamento, sempre com ALT alterada e sem remissão do quadro histológico. Relatam ainda os autores que, após a suspensão da terapêutica, o HBV-DNA voltou a ser detectado no soro $^{25}$. Concluem os autores que a lamivudina revelouse um potente inibidor da replicação do VHB mas mostrou-se incapaz de inibir a replicação do $\mathrm{VHD}^{25}$. A associação da lamivudina e altas doses de Inteferon por um período de 16 semanas também não melhorou a resposta terapêutica.

Estudos in vitro (sistema de cultura em célula) com trans-ribozimas e oligonucleotídios anti-sentido (antisense probes), utilizadas isoladas ou associadas ao Interferon alfa-2b, revelaram a capacidade dessas substâncias de inibir a replicação do HDV-RNA ${ }^{28}$. Neste estudo, observou-se eficácia inibitória do HDV-RNA de $25 \%$ com a ribozima, de $35 \%$ com os oligonucleotídios anti-sentido e de $47 \%$ com o interferon. Verificou-se aumento da eficácia do interferon na inibição do HDVRNA, quando na cultura de células havia a expressão basal de ribozima $(70 \%)$ ou de oligonucleotídios antisentido $(83 \%)$. Segundo os autores, o uso da combinação de ribozimas ou oligonucleotídios anti-sentido com o interferon representa nova promessa no tratamento não só da infecção pelo VHD, como também de outros vírus constituídos de RNA ${ }^{28}$.

\section{PROFILAXIA}

A imunização ativa (vacina) contra o VHB constitui o melhor procedimento para a redução da prevalência e incidência da infecção pelo $\mathrm{VHD}^{13}{ }^{4252}$. Todavia, a vacina mostra-se eficaz apenas na coinfecção (infecção simultânea $\mathrm{VHB}+\mathrm{VHD}$ ) entre indivíduos suscetíveis a infecção pelo VHB. Entre indivíduos portadores crônicos do VHB, residentes em áreas endêmicas de infecção pelo VHD, ou pertencentes a grupos de risco, a profilaxia da superinfecção pelo VHD continua representando desafio.

Os esquemas de vacinação, doses da vacina, e as indicações prioritárias na prevenção da infecção pelo
VHD são as mesmas do VHB. Citam-se, por exemplo, os grupos de risco (homem que faz sexo com homem, usuários de drogas ilícitas injetáveis, hemodializados) e principalmente indivíduos HBsAg negativos residentes em áreas endêmicas de infecção pelo VHB e VHD ${ }^{13} 42$. Nessas áreas, sugere-se a vacinação de todas as crianças recém-nascidas e com até nove anos de idade ${ }^{13}$.

A imunização passiva (imunoglobulina anti-HBs) contra - VHB vem sendo utilizada como medida profilática para evitar a infecção de novo pelo VHB e, conseqüentemente, a reinfecção pelo VHD em pacientes transplantados, por causa de doença hepática crônica $D^{42} 45$.

\section{REFERÊNCIAS BIBLIOGRÁFICAS}

1. Arboleda M, Castilho MC, Fonseca JCF, Albuquerque BC, Saboia RC, Yoshida CFT. Epidemiological aspects of hepatitis B and D virus in the northern region of Amazonas, Brazil. Transaction of the Royal Society Tropical Medicine and Hygiene 89: 481-483, 1995.

2. Bensabath G, Hadler SC, Pereira Soares MC, Fields H, Dias LB, Popper H, Maynard JE. Hepatitis Delta virus infection and Labrea hepatitis - Prevalence and role of fulminant hepatitis in the Amazon basin. Journal of the American Medical Association 258:479-483, 1987.

3. Borghesio E, Rosina F, Smedile A, Lagget M, Niro MG, Marinucci G, Rizzetto M. Serum immunoglobulin M antibody to hepatitis $D$ as a surrogate marker of hepatitis $D$ in interferon-treated patients and in patients who underwent liver transplantation. Hepatology 27: 873-876, 1998.
4. Braga WSM, Brasil LM, Souza RAB, Castilho MCC, Fonseca JCF. Ocorrência da infecção pelo vírus da hepatite $B(V H B)$ e delta (VHD) em sete grupos indígenas do Estado do Amazonas. Revista da Sociedade Brasileira de Medicina Tropical 34: 349-355, 2001.

5. Brasil LM, Botelho R, Castilho MC, Braga WSM, Borborema C, Ferreira L, Fonseca JCF. Estudo familiar de pacientes com hepatite fulminante pelos vírus da hepatite B (VHB) e D (VHD) na Amazônia ocidental. Archivos Argentinos de Enfermidades del Aparato Digestivo 10: 84, 1996.

6. Brunetto MR, Stemler M, Bonino F, Schodel F, Oliveri F, Rizzetto $M$, Verme $G$, Will H. A new hepatitis $B$ virus strain in patients with severe anti-HBe positive chronic hepatitis B. Journal of Hepatology 10:258-261, 1990.

7. Casey L, Brown TL, Colan EJ, Wignall F, Gerin JL. A genotype of hepatitis $D$ virus that occurs in northern America. Proceedings of the National Academy of Science USA 90: 9016-9020, 1993. 
8. Casey JL, Niro GA, Engle RE, Veja A, Gomez H, McCarthy, Watts DM, Hyams KC, Gerin JL. Hepatitis B virus (HBV)/hepatitis D. virus (HDV) coinfection in outbreaks of acute hepatitis in the Peruvian Amazon basin: The roles of HDV genotype III and HBV genotype F. Journal of Infectious Diseases 174:920-926, 1996.

9. Chen CJ, Tseng SF, Lu CF, Lin HC, You AL, Chen CS, Hwang SJ, Hsieh SF, Hsu ST. Current seroepidemiology of hepatitis Delta virus infection among hepatitis B surface antigen carriers of general and high risk populations in Taiwan. Journal of Medical Virology 38: 97-101, 1992.

10. Crosignani A, Invernizi P, Ferrari R, Manzin A, Bruno S, Zuin M, Bianchi FB, Podda M. Exacerbation of chronic hepatitis D during interferon alpha administration. Italian Journal of Gastroenterology and Hepatology 31: 66-69, 1999.

11. Di Marco V, Giacchino R, Timitilli A, Bortolotti F, Crivellaro $C$ Calzia R, lanuzzi C, Prestileo T, Vajro P, Nebbia G, Stringhi A Rosina F, Biassoni D, Callea F, Rizzetto M, Craxi A. Long term interferon- alpha treatment of children with chronic hepatitis Delta: a multicentre study. Journal of Viral Hepatitis 3: 123-128, 1996.

12. Farci P, Mandas A, Coiana A, Lai ME, Desmet V, Eyken PV, Gibo Y, Caruso L, Scaccabarozzi S, Criscuolo D, Ryff JC, Balestrieri A. Treatment of chronic hepatitis D with IFN alpha -2a. New England Journal of Medicine 330: 88-94, 1994.

13. Fonseca JCF. Hepatite Delta. In: Fonseca JCF (ed) Hepatite Delta. Imprensa Universitária, Manaus, AM, p.1-66. 1993.

14. Fonseca JCF, Brasil LM, Castilho MC, Braga WSM, Souza RAB Hepatitis delta virus (HDV) infection in the Brazilian Amazon basin and its role in chronic liver disease. Hepatology 19: 63I, 1994.

15. Fonseca JCF, Brasil LM, Castilho MC, Souza RAB, Braga WSM. The occurrence of increased rates of HAV, HBV and HDV infection in an isolated village, Ipixuna, Amazonas Brazil. Hepatology 19: 63I, 1994

16. Fonseca JCF, Brasil LM, Castilho MC, Botelho R, Braga WM, Ferreira LC. Fulminant hepatitis and microvesicular steatosis (morula-like cells). A study in children and adolescents. Hepatology 30:284A, 1999.

17. Fonseca JCF, Castilho MC, Souza RAB, Brasil LM, Braga WSM Significado da fração $\operatorname{lgM}$ anti-HD em pacientes com hepatite crônica Delta. Gastroenterologia Endoscopia Digestiva14: 144, 1995.

18. Fonseca JCF, Ferreira LCL, Brasil LM, Castilho MC, Moss $R$, Barone M. Fulminant Labrea hepatitis: Role of HAV, HBV and HDV infection. Revista do Instituto de Medicina Tropical de São Paulo 34: 609-612, 1992.

19. Fonseca JCF, Simonetti SRR, Schatzmayr HG, Castejón MJ, Cesário ALO, Simonetti JP. Prevalence of infection with hepatitis Delta virus (HDV) among carriers of hepatitis B surface antigen in Amazonas State, Brazil. Transactions of the Royal Society of Tropical Medicine and Hygiene 82: 469-471, 1988.

20. Garripoli A, Di Marco V, Cozzolongo R, Costa C, Sedile A, Fabiano A, Bonino F, Rizzetto M, Verme G, Craxi A. Ribavirin treatment for chronic hepatitis D: A pilot study. Liver 14:154 -157, 1994.

21. Hadler SC, Monzon M, Ponzetto A, Anzola R, Rivero D, Mandolfi A, Bracho A, Francis DP, Gerber MA, Thung S, Gerin J, Maynard JE, Popper H, Purcell RH. Delta virus infection and severe hepatitis. An epidemic in the Yucpa indians of Venezuela. Annals of Internal Medicine 100: 339-344, 1983.
22. Honkoop P, de Man RA, Niesters HGM, Heijtink RA, Schalm SW. Lamivudine treatment in patients with chronic hepatitis Delta infection. Hepatology 26:433A, 1997.

23. Jardi R, Rodriguez R, Buti M, Costa X, Cotrina M, Galimany R, Esteban R, Guardia J. Role of hepatitis B, C, and D viruses in dual and triple infection: Influence of viral genotypes and hepatitis $B$ precore and basal core promoter mutations on viral replicative interference. Hepatology 34: 404-410, 2001.

24. Lai MCC. Molecular biologic and pathogenetic analysis of hepatitis Delta virus. Journal of Hepatology 22:127-131, 1995.

25. Lau D T-Y, Doo E, Park Y, Kleiner DE, Schmid P, Kuhns MC, Hoofnagle JH. Lamivudine for chronic Delta Hepatitis. Hepatology 30:546 -549, 1999

26. Lau DT, Kleiner DE, Park Y, Di Bisceglie AM, Hoofnagle JH. Resolution of chronic delta hepatitis after 12 years of interferon alfa therapy. Gastroenterology 117: 1229-1333, 1999.

27. Lesbordes JL, Trepo C, Ravisse P, Chevalier P, Beuzit Y, Vohito MD, Meunier DMY, Gonzalez JP, Sepetjan M, Georges AS. Infection with hepatitis Delta virus in Bangui. New England Journal of Medicine 314: 517-518, 1986.

28. Madejón A, Bartolomé J, Carreño V. In vitro inhibition of the hepatitis delta virus replication mediated by interferon and transribozyme or antisense probes. Journal of Hepatology 29:385393, 1998

29. Madejón M, Cotonat T, Bartolomé J, Castillo I, Carreño V. Treatment of chronic hepatitis $D$ virus infection with low and high doses of Interferon alfa 2a: utility of polymerase chain reaction in monitoring antiviral response. Hepatology 19:1331-1336, 1994.

30. Negro F, Rizzetto M. Diagnosis of hepatitis delta virus infection. Journal of Hepatology 22:136-139, 1995.

31. Niro AG, Casey JL, Gravinese E, Garrubba M, Conoscitore P, Sagnelli E, Durazzo M, Caporaso N, Perri F, Leandro G, Facciorusso, Rizzetto M, Andriulli A. Intrafamilial transmission of hepatitis delta virus: molecular evidence. Journal of Hepatology 30: 564-569,1999.

32. Niro GA, Smedile A, Andriulli A, Rizzetto M, Gerin JL, Casey JL. The predominance of hepatitis Delta virus genotype I among chronically infected Italian patients. Hepatology 25:728-734, 1997.

33. Oliviero S, D'adamio L, Chiarberge E, Brunetto R, Smedile A, Marchi M, Negro F, Bonino F. Characterization of hepatitis Delta antigen gene of a highly pathogenic strain of hepatitis Delta virus. Progress in Clinical and Biological Research 364:321-325, 1991.

34. Orlando R, Tosone G, Tiseo D, Conte MCD, Scordino F, Vechi RM, Filippo G, Montesano M, Piazza M. Prolonged therapy with beta interferon in patients with chronic delta hepatitis. Journal of Hepatology 30: 250, 1999.

35. Philipp T, Straub P, Durazzo M, Tukey RH, Manns MO. Molecular analysis of autoantigens in hepatitis D. Journal of Hepatology 22: 132-135, 1995.

36. Picciotto A, Campos N, Caglieris S, Dardano G, Mondello L, Testa $R$, Valente $U$, Celle $G$. Pre or post liver transplant (olt) lamivudine therapy in patients with hepatitis B virus (HBV) replication. Hepatology 26: 582A, 1997.

37. Ponzetto A, Hoyer BH, Popper H, Engle R, Purcell RH, Gerin JL. Tritation of the infectivity of hepatitis Delta virus in chimpanzees. Journal of Infectious Diseases 155:72-78, 1987. 
38. Puoti M, Rossi S, Forleo MA, Zaltron S, Spinetti A, Putzolu V, Rodella A, Carosi G. Treatment of chronic hepatitis D with interferon alpha- $2 \mathrm{~b}$ in patients with human immunodeficiency virus infection. Journal of Hepatology 29:45-52, 1998.

39. Quintero A, Uzcategui N, Loureiro CL, Villegas L, Illarramendi X, Guevara ME, Ludert JE, Blitz I, Liprandi F, Pujol FH. Hepatitis delta virus genotypes I and III circulate associated with hepatitis $B$ virus genotype $F$ in Venezuela. Journal of Medical Virology 64: 356-359, 2001.

40. Radjef N, Ivannuishina V, Anais P, Trinchet J, Deny P. Hepatitis D virus (HDV) genome analysis from Africa suggest the existence of more than three world-wide genotypes. Journal of Hepatology 34 (suppl 1): 120, 2001.

41. Rizzetto M. Hepatitis Delta: The virus and disease. Journal of Hepatology 11: 145-148, 1990.

42. Rizzeto M, Canese MG, Aricó S, Crivelli C, Trepo C, Bonino F, Verme G. Immunofluorescence detection of a new antigen/antibody system (Delta/anti-Delta) associated with hepatitis B virus in liver and serum of HBsAg carriers. GUT 18: 997-1003, 1977.

43. Rizzetto M, Macagno S, Chiaberge E, Negro F, Giacomo C, Doglia M, Macagno S, Verme G, Marinucci G, Alfani D, Milazzo F, Fassati LR. Liver transplantation in hepatitis Delta virus disease. Lancet 2: 469-471, 1987.

44. Sagnelli E, Stroffolini T, Ascione A, Chiaramonte M, Craxi A, Giusti G, Piccinino F. Decrease in HDV endemicity in Italy. Journal of Hepatology $26: 20-24,1997$.

45. Saigal S, Smith HM, Heaton ND, Devlin J. Suppression of hepatitis $B$ and hepatitis $C$ viraemia by concurrent delta virus infection: its beneficial effect on the outcome of orthotopic liver transplantation. Hepatology 30: 302A, 1999.
46. Samuel D, Zignego AL, Reynes M, Feray C, Arulnaden JL, David MF, Gigou M, Bismuth A, Mathieu D, Gentilini P, Benhamou JP, Brechot $\mathrm{C}$, Bismuth $\mathrm{H}$. Long-term clinical and virological outcome after liver transplantation for cirrhosis caused by chronic delta hepatitis. Hepatology 21: 333-339, 1995.

47. Shakil AO, Hadziyannis S, Hoofnagle JH, Di Bisceglie AM, Gerin $\mathrm{JL}$, Casey JL. Geographic distribution and genetic variability of hepatitis Delta virus Genotype I. Virology 234:160-167, 1997.

48. Smedile A, Casey JL, Cote PJ, Durazzo M, Lavezzo B, Purcell $\mathrm{R}$, Rizzetto M, Gerin JL. Hepatitis D viremia following orthotopic liver transplantation involves a typical HDV virion with a hepatitis B surface antigen envelope. Hepatology 27:1723 -1729, 1998.

49. Wolters LMM, Van Nunen AB, Honkoop P, Vossen ACTM, Niesters HGM, Zonderuvan PE, Man RA. Lamivudine-high dose interferon combination therapy for chronic hepatitis $B$ patients co-infected with the hepatitis D virus. Journal of Viral Hepatitis 7: 428-434, 2000.

50. Wu JC, Chen CM, Sheen IJ, lee SD, Tzeng HM, Choo KB. Evidence of transmission of hepatitis Delta virus to spouses from sequence analysis of the viral genome. Hepatology 22:1656-1660, 1995.

51. Wu JC, Chiang TY, Sheen IJ. Characterization and phylogenic analysis of a novel hepatitis $\mathrm{D}$ virus group discovered by restriction fragment length polymorphism. Journal of General Virology 78: 1105-1113, 1998.

52. Wu JC, Choo KB, Chen CM, Chen TZ, Huo T, Lee SD. Genotyping of hepatitis $D$ virus by restriction-fragment length polymorphism and relation to outcome of hepatitis D. Lancet 346: 939-941, 1995.

53. Zhang YY, Tsega E, Hansson BG. Phylogenetic analysis of hepatitis $D$ viruses indicating a new genotype I subgroup among African isolates. Journal of Clinical Microbiology 34: 3023-3030, 1996. 